Research article

Open Access

\title{
The human anti-IL-1 $\beta$ monoclonal antibody ACZ885 is effective in joint inflammation models in mice and in a proof-of-concept study in patients with rheumatoid arthritis
}

\author{
Rieke Alten ${ }^{1}$, Hermann Gram², Leo A Joosten³, Wim B van den Berg' ${ }^{3}$ Joachim Sieper ${ }^{4}$, \\ Siegfrid Wassenberg'5, Gerd Burmester6, Piet van Riel7, Maria Diaz-Lorente ${ }^{8}$, Gerardus JM Bruin 8 , \\ Thasia G Woodworth ${ }^{8}$, Christiane Rordorf ${ }^{8}$, Yannik Batard ${ }^{8}$, Andrew M Wright ${ }^{8}$ and Thomas Jung ${ }^{8}$
}

1Department of Internal Medicine II, Rheumatology, Schlosspark-Klinik Teaching Hospital Charité University Medicine Berlin, Heubnerweg, D-14059 Berlin, Germany

${ }^{2}$ Novartis Institutes of Biomedical Research, Basel, CH-4002 Basel, Switzerland

${ }^{3}$ Rheumatology Research and Advanced Therapeutics, Radboud University Nijmegen Medical Centre, Nijmegen 6500 HB, The Netherlands

${ }^{4}$ Department of Rheumatology, Klinikum Benjamin Franklin, Hindenburgdamm, D-12200 Berlin, Germany

${ }^{5}$ Department of Rheumatology, Evangelisches Fachkrankenhaus, Rosenstraße, D-40882 Ratingen, Germany

${ }^{6}$ Department of Rheumatology, Charité, Charitéplatz, D-10117 Berlin, Germany

7Department of Rheumatology, University Medical Center St Radboud, Nijmegen $6500 \mathrm{HB}$, The Netherlands

8 Novartis Exploratory Development, Werk St. Johann, Forum 1, CH-4002 Basel, Switzerland

Corresponding author: Thomas Jung, thomas.jung@novartis.com

Received: 2 Jan 2008 Revisions requested: 25 Feb 2008 Revisions received: 16 Apr 2008 Accepted: 5 Jun 2008 Published: 5 Jun 2008

Arthritis Research \& Therapy 2008, 10:R67 (doi:10.1186/ar2438)

This article is online at: http://arthritis-research.com/content/10/3/R67

(c) 2008 Alten et al.; licensee BioMed Central Ltd.

This is an open access article distributed under the terms of the Creative Commons Attribution License (http://creativecommons.org/licenses/by/2.0), which permits unrestricted use, distribution, and reproduction in any medium, provided the original work is properly cited.

\begin{abstract}
Introduction IL-1 $\beta$ is a proinflammatory cytokine driving joint inflammation as well as systemic signs of inflammation, such as fever and acute phase protein production.

Methods ACZ885, a fully human monoclonal antibody that neutralizes the bioactivity of human IL-1 $\beta$, was generated to study the potent and long-lasting neutralization of IL-1 $\beta$ in mechanistic animal models as well as in a proof-of-concept study in patients with rheumatoid arthritis (RA).

Results The mouse IL-1 receptor cross-reacts with human IL$1 \beta$, and it was demonstrated that ACZ885 can completely suppress IL-1 $\beta$-mediated joint inflammation and cartilage destruction in mice. This observation prompted us to study the safety, tolerability and pharmacodynamic activity of ACZ885 in RA patients in a small proof-of-concept study - the first to be conducted in humans. Patients with active RA despite treatment with stable doses of methotrexate were enrolled in this dose escalation study. The first 32 patients were split into four cohorts of eight patients each (six were randomly assigned to active treatment and two to placebo). ACZ885 doses were 0.3, 1,3 and $10 \mathrm{mg} / \mathrm{kg}$, administered intravenously on days 1 and 15. To explore efficacy within 6 weeks of treatment, an
\end{abstract}

additional 21 patients were randomly assigned to the $10 \mathrm{mg} / \mathrm{kg}$ cohort, resulting in a total of 20 patients dosed with $10 \mathrm{mg} / \mathrm{kg}$ and 15 patients treated with placebo. There was clinical improvement (American College of Rheumatology 20\% improvement criteria) at week 6 in the $10 \mathrm{mg} / \mathrm{kg}$ treatment group; however, this did not reach statistical significance $(P=$ 0.085). A statistically significant reduction in disease activity score was observed after 4 weeks in the $10 \mathrm{mg} / \mathrm{kg}$ group. Onset of action was rapid, because most responders exhibited improvement in their symptoms within the first 3 weeks. Creactive protein levels decreased in patients treated with ACZ885 within 1 week. ACZ885 was well tolerated. Three patients receiving ACZ885 developed infectious episodes that required treatment. No anti-ACZ885 antibodies were detected during the study.

Conclusion ACZ885 administration to methotrexate-refractory patients resulted in clinical improvement in a subset of patients. Additional studies to characterize efficacy in RA and to determine the optimal dose regimen appear warranted.

Trial Registration ClinicalTrials.gov identifier NCT00619905.

$\overline{\mathrm{ACR}}=$ American College of Rheumatology; $\mathrm{CRP}=\mathrm{C}$-reactive protein; DAS28 = Disease Activity Score using 28 joint counts; $\mathrm{ED}_{50}=$ dose effective to achieve a mean of $50 \%$ improvement; EULAR = European League Against Rheumatism; $h=$ human; IL = interleukin; IL-1Ra $=\mathrm{IL}-1$ receptor antagonist; RA = rheumatoid arthritis; TNF = tumour necrosis factor. 


\section{Introduction}

Rheumatoid arthritis (RA) is a chronic inflammatory disease of the joints that is associated with destruction of cartilage and bone. In addition to its local destructive nature, it also can have a pronounced systemic inflammatory component, presenting as fever, headache and fatigue, and may even affect other organs such as the skin, liver, spleen and lymph nodes. The contribution made by proinflammatory cytokines such as tumour necrosis factor (TNF)- $\alpha$ and IL-1 has been validated in preclinical animal models and in humans $[1,2]$.

Current therapy targeting $\mathrm{LL}-1$ in $\mathrm{RA}$ is based on a recombinant form of the IL-1 receptor antagonist (IL-1Ra; anakinra), which binds to the IL-1 receptor without eliciting a signal and therefore competes with the binding of the two natural ligands, namely IL- $1 \alpha$ and IL-1 $\beta$. As compared with TNF- $\alpha$ inhibitors, it appears that treatment with the recombinant IL-1 Ra is less efficacious in RA [3]. However, it is unclear whether this is due to biological superiority of TNF- $\alpha$ over IL- 1 in RA pathogenesis [4] or whether the approach to block the IL-1 receptor with anakinra is only partly effective in neutralizing IL-1 activity in vivo because of short half-life or inability to achieve sufficient exposure at the target site with the current dosing regimen [5].

The main elicitor of inflammatory responses in preclinical animal models appears to be IL-1 $\beta$ and not IL- $1 \alpha$. In murine collagen-induced arthritis [6] and antigen-induced arthritis [7,8], inflammation and cartilage degradation were inhibited by blocking IL- $1 \beta$ but not IL-1 $\alpha$. In RA patients, IL-1 $\beta$ is overexpressed in inflamed synovial tissue, in particular in the lining layer and in sublining cells [9], and it is elevated in draining lymph from affected joints [10]. Furthermore, IL-1 $\beta$ is localized to the synovial pannus in close proximity to bone and cartilage [11], and cartilage from arthritis patients exhibits upregulation of IL-1 $\beta$ mRNA as compared with normal cartilage. Increased levels of IL-1 $\beta$ in synovial fluid [12] have been described and were found to correlate with histological features of RA $[13,14]$. Treatment with anakinra demonstrated improvement in histological characteristics of RA joint pathology [15], and evidence was provided that it delays the progression of radiographic joint damage [16]. Thus, there is reason to believe that $\mathrm{IL}-1 \beta$ is a crucial cytokine that drives inflammation and joint destruction in RA.

We report here results of preclinical studies and a proof-ofconcept study in patients with RA, using a fully monoclonal antibody (ACZ885) directed against human IL-1 $\beta$. ACZ885 is expected to have the half-life of a typical $\lg _{1}$ antibody, thus ensuring full neutralization of IL-1 $\beta$ over a longer period of time as compared with recombinant IL-1Ra; the therefore study explored pharmacodynamic effects in RA patients (secondary to an evaluation of safety).

\section{Materials and methods In vivo activity of ACZ885 in a human IL-1 $\beta$-dependent mouse model of joint inflammation}

Cells of the murine fibroblast line $3 \mathrm{~T} 3 \mathrm{NIH}$ were transfected with retroviral vector DFG-hlL-1 $\beta$-neo, which contains the cDNAs for human (h)IL-1 $\beta$ and neomycin phosphotransferase $\left(\right.$ neo $\left.^{\mathrm{R}}\right)$, as described previously [17]. The 3T3NIH fibroblast cell line was derived from a DBA background. One clone derived from the transduction, namely IB2 (3T3-hIL-1 $\beta$ ), was selected, which produced high levels of hlL-1 $\beta$ (220 ng hlL$1 \beta / 24$ hours per $10^{6}$ cells) in vitro. hlL-1 $\beta$-induced arthritis was induced by intra-articular injection of $10^{4} \mathrm{IB} 2$ cells into the right knee joints of DBA-1 mice. Mice were injected with ACZ885 or isotype control antibody CHI621, which is specific for human CD25 and does not cross-react with mouse cells or tissue. All mice were housed in filter top cages, and water and food were supplied ad libitum. The mice were studied at age 10 to 14 weeks. All animal experiments were approved by the Nijmegen University Animal Ethics Committee.

Administration of antibodies was intraperitoneal 2 hours before intra-articular injection of the IB2 clone. Joint inflammation was quantified using the $99 \mathrm{mT}$ c uptake method [18]. By external gamma counting, this method measures the accumulation of a small radioisotope at the site of inflammation caused by locally increased blood flow and tissue swelling. The severity of inflammation is expressed as the ratio of 99mTc uptake in the right (inflamed) to that in the left (control) knee joint.

Proteoglycan synthesis was assayed as follows. Patellae with minimal surrounding tissue were placed in RPMI 1640 medium with glutamax, gentamycin $(50 \mu \mathrm{g} / \mathrm{ml})$ and ${ }^{35} \mathrm{~S}$-sulphate $(0.74 \mathrm{MBq} / \mathrm{ml})$. After 3 hours of incubation at $37^{\circ} \mathrm{C}$ in a carbon dioxide incubator, patellae were washed in saline three times, fixed in 4\% formaldehyde and subsequently decalcified in $5 \%$ formic acid for 4 hours. Patellae were punched out of the adjacent tissue, dissolved in $0.5 \mathrm{ml}$ Luma Solve at $65^{\circ} \mathrm{C}$ (Omnilabo, Breda, The Netherlands), and after addition of 10 $\mathrm{ml}$ Lipoluma (Omnilabo) the ${ }^{35} \mathrm{~S}$ content was measured using liquid scintilation counting. For histological analysis, whole knee joints were removed and fixed in 4\% formaldehyde for 7 days before decalcification in 5\% formic acid and processing for paraffin embedding. Tissue sections $(7 \mu \mathrm{m})$ were stained with haematoxylin/eosin or safranin $\mathrm{O} /$ fast green. Histopathological changes in the knee joints were scored in the patella/ femur region on five semi-serial sections, spaced $140 \mu \mathrm{m}$ apart. Scoring was performed on decoded slides by two separate observers, using the following parameters. In the haematoxylin/eosin stained slides the amount of cells infiltrating the synovial lining and the joint cavity was scored from 0 to 3 . Proteoglycan depletion was scored in the safranin $\mathrm{O}$ stained slides on a scale from 0 to 3 (ranging from stained cartilage to fully destained cartilage). Cartilage damage was scored from 0 to 3 (ranging from unaffected cartilage to maximum chondrocyte death and cartilage destruction). 


\section{Design of clinical study}

This was a randomized, double-blind, placebo-controlled, dose escalation study conducted to explore the safety, tolerability, pharmacokinetics and pharmacodynamics of ACZ885 in patients with active RA, despite ongoing treatment with a stable dose of methotrexate (MTX) of $15 \mathrm{mg} /$ week or more for at least 3 months (CACZ885A2101). It is the first of its kind to be conducted in humans. Patients receiving stable doses of $10 \mathrm{mg} /$ week methotrexate could be included if the patients could not tolerate higher doses.

Included patients were required to have a diagnosis of RA (American College of Rheumatology [ACR] 1987 revised classification for criteria for RA) with a disease duration of at least 6 months before randomization; active disease at screening; baseline evaluation (same evaluator) indicating more than six tender and six swollen joints out of 28 examined (including any effused joint); and either Westergren erythrocyte sedimentation rate of $28 \mathrm{~mm} /$ hour or greater, or C-reactive protein (CRP) of at least $6 \mathrm{mg} / \mathrm{l}$. The inclusion criteria also required patients were have failed at least one disease-modifying antirheumatic drug in the past, but not deemed 'refractory to all therapies'. Their current treatment regimen included at least $15 \mathrm{mg}$ methotrexate/week and with the current dose stable for approximately 3 months. Patients were required to have an otherwise stable RA therapeutic regimen, consisting of either a stable dose of nonsteroidal anti-inflammatory drugs and/or a stable dose of oral corticosteroids (prednisone or equivalent $<$ $10 \mathrm{mg} /$ day) for at least 4 weeks before randomization.
This multicentre study was conducted in accordance with GCP (Good Clinical Practice) guidelines and the Helsinki Declaration in three countries in Europe. The study protocol and patient informed consent form was approved by local ethics committees and health authorities. The primary objective was to evaluate the safety and tolerability of ACZ885 administered as an intravenous infusion. Secondary objectives included assessment of the preliminary biologic activity/pharmacodynamics of ACZ885 using ACR criteria for clinical response and Disease Activity Score using 28 joint counts (DAS28), evaluation of the pharmacokinetics of ACZ885 and examination of the potential immunogenicity of ACZ885.

The initial dose escalation phase of the study consisted of four cohorts (Figure 1). In each cohort six patients were randomly assigned to receive ACZ885 and two patients were randomly assigned to receive placebo. In the first cohort, patients randomly assigned to ACZ885 received $0.3 \mathrm{mg} / \mathrm{kg}$ intravenously on days 1 and 15. Safety data from a minimum of six out of eight patients in this cohort up to day 20 were reviewed prior to proceeding with the study and starting the next higher dose. Patients randomly assigned to ACZ885 in the second cohort received $1 \mathrm{mg} / \mathrm{kg}$, in the third cohort $3 \mathrm{mg} / \mathrm{kg}$, and finally in the fourth cohort $10 \mathrm{mg} / \mathrm{kg}$. Safety data from the $10 \mathrm{mg} / \mathrm{kg}$ cohort were found to raise no concern that might prevent proceeding with the study, so this cohort was extended to increase the sample size, such that in total 20 patients received $10 \mathrm{mg} / \mathrm{kg}$ intravenous on days 1 and 15, and a total of 15 patients received placebo. Thus, a total of 53 patients with RA were enrolled.

Figure 1

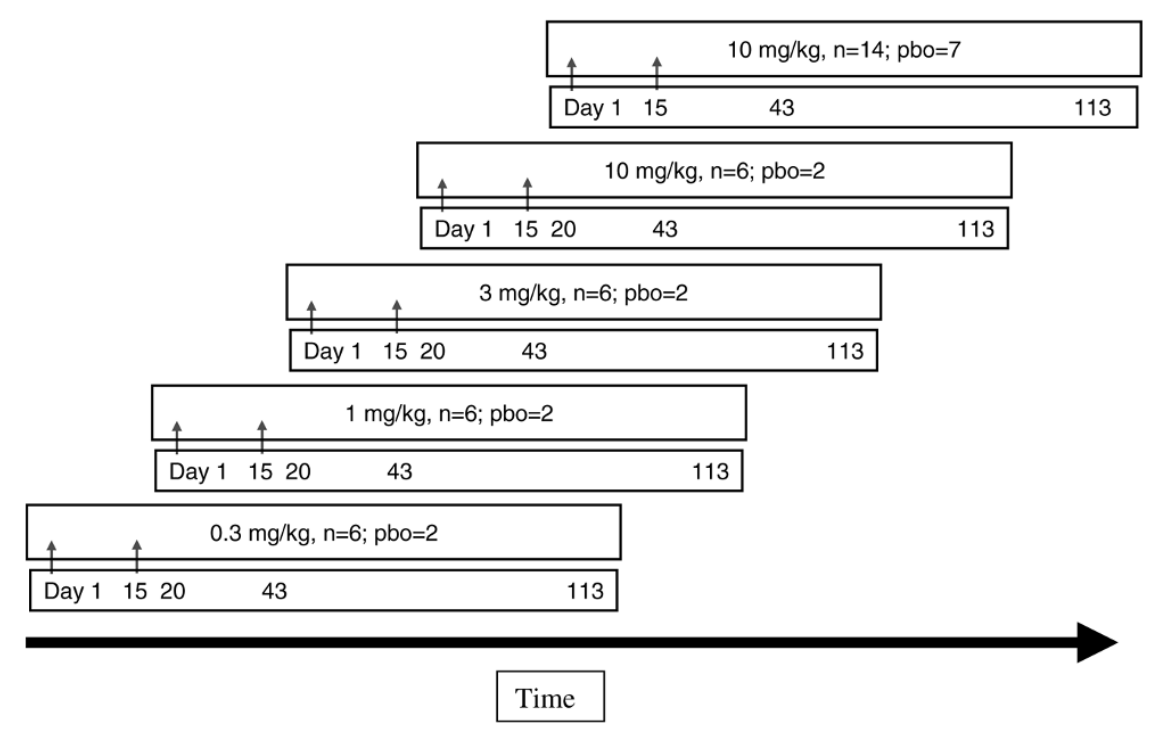

Study design. Sequential dose-escalation, randomized, double-blind, placebo controlled study design with an extension at the highest dose level. ACZ885 was administered intravenously on days 1 and 15 (arrows). Safety data generated up to day 20 in each cohort were reviewed before escalating to the next higher dose level. Independent observer efficacy assessments were made at day 1 , before dosing, and day 43 , in addition to weekly investigator assessments up to Day 43. The end of study was on day 113. After safety review of the first six patients at $10 \mathrm{mg} / \mathrm{kg}$, an extension cohort was started, which included 14 patients on ACZ885 and seven patients on placebo (pbo). 
ACR response criteria were evaluated at baseline and on days $8,15,22,29$ and 43 by the investigator, and at baseline and day 43 by a blinded observer at each site who was not otherwise involved in the study. Overall, there was no evidence of a systematic bias between the blinded observer and the investigator assessments. Patients were further followed for safety and pharmacokinetic assessments, and a formal end of study was reached at day 113. Investigators were free to change treatment after day 43 as they deemed necessary.

\section{Statistical analyses}

Statistical analyses were performed on the ACR 20\%, 50\% and $70 \%$ response criteria (ACR20, ACR50 and ACR70) rates. Separate statistical analyses were performed on the response rate at day 43 (assessed by a blinded observer) and the response rate up to and including day 43. Fisher's exact test was used to compare treatment groups. From these analyses, one sided $P$ values are presented. The primary comparison was the comparison between the $10 \mathrm{mg} / \mathrm{kg}$ treatment group and placebo at day 43. For the DAS28 measurements, a repeated measures mixed effect analysis was performed. Baseline DAS28 was included in the model as a covariate. An unstructured correlation structure was assumed to adjust for correlation within patients. From this model the adjusted mean difference for each treatment group versus placebo at each time point was calculated, along within its $95 \%$ confidence interval. No multiplicity adjustments were made to the confidence intervals. A similar analysis was performed on the CRP measurements; however, because of the skewness of the CRP measurements, the analysis was performed on the $\log _{e}$ scale and results were back-transformed onto the original scale.

The inclusion of six patients per dose group in each escalation step provided an $80 \%$ probability that at least one patient would report an adverse event that has an underlying incidence rate of $24 \%$. With 20 patients receiving the highest ACZ885 dose (six patients in the last escalation step plus 14 patients in the expansion phase) and 15 patients receiving placebo (two patients in each of the four escalation steps plus seven patients in the expansion phase), there was at least $80 \%$ power to detect a statistically significant difference in ACR20 response rate comparing ACZ885 with placebo, assuming an underlying odds ratio of 6 , a $5 \%$ significance level and a one-side test approach. Given an anticipated placebo ACR20 response rate of 20\%, an odds ratio of 6 would translate into an ACR20 response rate of $60 \%$ for the ACZ885 treatment group.

\section{Results \\ ACZ885 is a human antibody that binds to human IL-1 $\beta$ with high affinity and neutralizes human IL-1 $\beta$ in vitro and in vivo}

ACZ885 was derived by subjecting genetically engineered mice carrying part of the human immunoglobulin repertoire to immunization with human IL-1 $\beta$. The antibody was initially identified from a hybridoma derived from these mice because of its ability to bind human IL-1 $\beta$ with high affinity (about $40 \mathrm{pmol} / \mathrm{l}$ ). No cross-reactivity toward rodent IL- $1 \beta$ or human IL- $1 \alpha$ was observed for ACZ885. The antibody was found to neutralize the bioactivity of human IL-1 $\beta$ on primary human fibroblasts in vitro with an $50 \%$ inhibitory concentration of $44.6 \mathrm{pmol} / \mathrm{l}$ (7.1 $\pm 0.56 \mathrm{ng} / \mathrm{ml} ; n=6)$.

IL- $1 \beta$ requires highly potent antagonists in large excess to neutralize its biological activity in vivo. Anti-cytokine antibodies with low neutralizing capacity can potentially lead to enhanced bioactivity of the targeted cytokine by prolonging its half-life in vivo [19]. In light of this potential complication, we considered demonstration that ACZ885 is devoid of any biologically relevant carrier effect in an in vivo model to be an important prerequisite for conducting clinical trials. Therefore, we created an artificial mouse model of joint inflammation that relies upon continuous secretion of human IL- $1 \beta$ by transfected mouse NIH3T3 cells injected into one knee joint. Whereas IL-1 $\beta$ driven inflammation becomes apparent after 24 hours and leads to total destruction of the joint within 7 to 10 days, controlateral joints or joints receiving control 3T3 cells do not exhibit signs of inflammation. Application of ACZ885 intraperitoneally 2 hours before injecting the IL-1 $\beta$ producing cells completely suppressed joint swelling, with a $50 \%$ effective dose (the dose effective to reduce inflammation by a mean of $50 \% ; E_{50}$ ) of $0.06 \mathrm{mg} / \mathrm{kg}$ (Figure 2a). Also, treatment with ACZ885 restored the ability of cartilage explants to synthesize proteoglycan, which is otherwise suppressed in IL-1 $\beta$ exposed cartilage (Figure $2 b$ ). In addition, histopathology taken at day 3 after injection of 3T3-hlL-1 $\beta$ cells revealed that administration of AC885 protected against severe joint destruction (Figure 2c). Apart from the strong reduction of the joint inflammation (numbers of cells in the synovial tissues), no bone erosion was noted in the AC885 treated animals compared with controls. Thus, ACZ885 has sufficient potency to neutralize fully the biological activity of human IL-1 $\beta$, even when it is produced at high concentrations in vivo, and it does not significantly prolong IL-1 activity.

\section{Proof-of-concept clinical trial in patients with RA}

A proof-of-concept study to explore safety and tolerability, pharmacokinetics and pharmacodynamics was conducted in patients with established RA with ongoing disease despite stable treatment with MTX. (Some of the data from this study were presented at EULAR [European League Against Rheumatism] in 2006 [20].) An overview of patient demographics at baseline is given in Table 1, and the design of the study is presented in Figure 1.

In the $10 \mathrm{mg} / \mathrm{kg}$ cohort there were six out of 19 (32\%) ACR20 responders at day 43 , as assessed by the blinded observer, versus one out of $15(7 \%)$ in the placebo group (one-sided $P$ $=0.085$; Table 2). ACR50 and ACR70 improvements were 
Figure 2

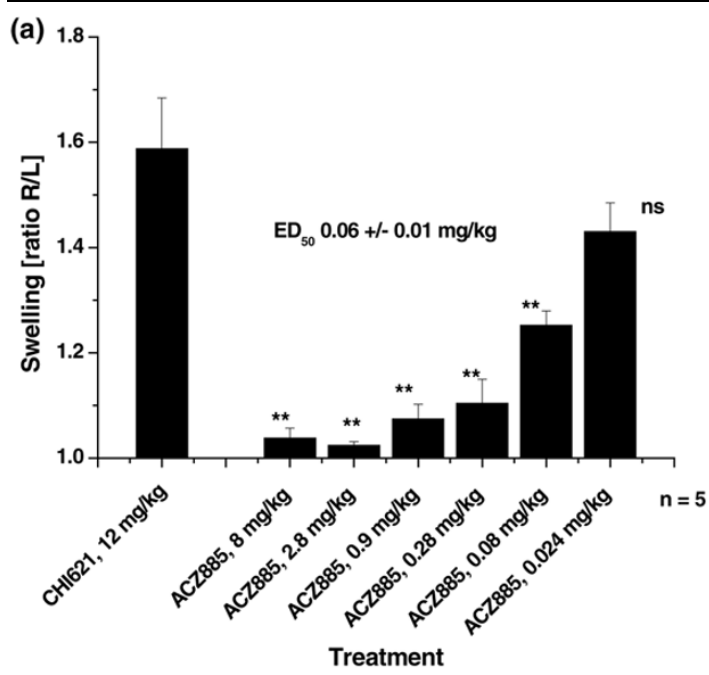

(b)

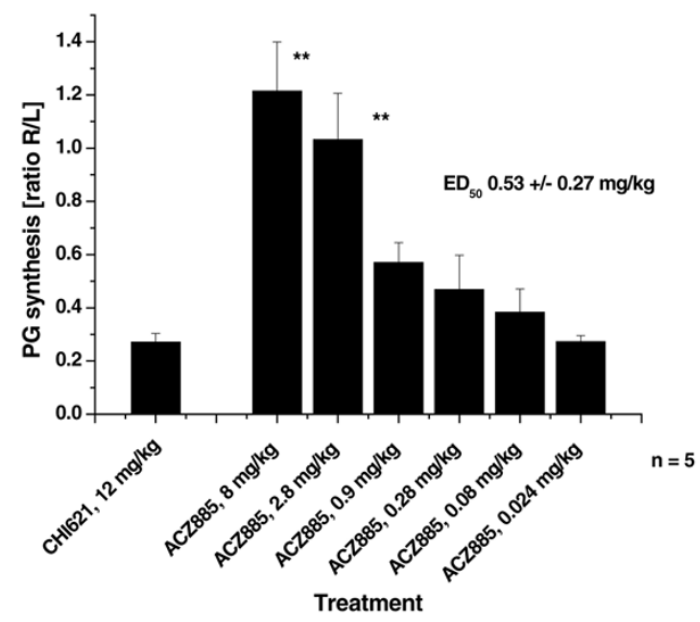

(c) Isotype Control

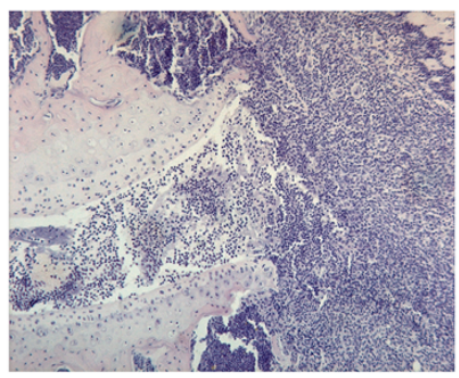
ACZ885

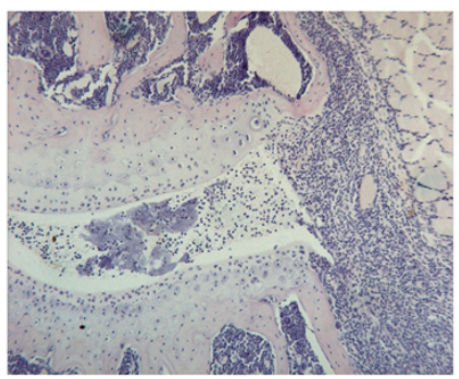

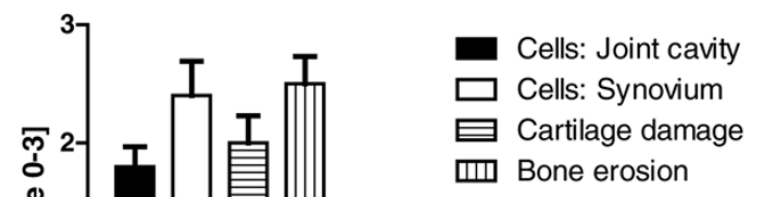

Blocking of IL-1 in mouse models of arthritis. (a) Inhibition of swelling. Mice were given different doses of ACZ885 or a control anti-CD25 antibody $(\mathrm{CHI} 621,12 \mathrm{mg} / \mathrm{kg}$ ) intraperitoneally before injection of 10,000 3T3-hulL-1 $\beta$ cells into the right hind knee joint. Swelling was measured 3 days after cell injection (as described in Materials and methods) and is expressed as the ratio between the right (treated) and left (untreated) joint. The results presented represent the mean \pm standard error or the mean (SEM; $n=5$ ). ${ }^{\star \star} P<0.01$ by analysis of variance followed by Dunnett's test for multiple comparisons post hoc. NS, not significant. (b) Proteoglycan (PG) synthesis by chondrocytes in explanted patellae was measured by incorporation of ${ }^{35} \mathrm{~S}$ labelled sulphate in isolated cartilage from treated (right) and untreated (left) knee joints. The results are given as the ratio of ${ }^{35} \mathrm{~S}$ incorporation between right and left knee cartilage and represent the mean \pm SEM $(n=5)$. Statistical analysis of the treated groups versus the control group (CHI621) was performed by analysis of variance followed by Dunnett's test for multiple comparisons post hoc. ${ }^{\star} P<0.05 ;{ }^{\star \star} P<0.01$. ED 50 , dose needed to achieve a mean of $50 \%$ effect. (c) Histology was analyzed at day 3 after local injection of 3T3-hIL-1 $\beta$ producing cells. Section of a mouse knee joint treated with isotype control antibody or AC885 are shown. Hematoxylin and eosin staining, original magnification (200x). Quantitative evaluation of the slides was done as described in Materials and methods and is presented in the graph. $n=5$ joints per group; all comparisons between active and control were significant $(P<0.05$, Mann-Whitney U-test).

observed at the highest dose levels ( 3 and $10 \mathrm{mg} / \mathrm{kg}$ ) in a total of four out of 25 patients, but no such responses were observed in the placebo group. Using the investigator assessments, 10 out of 20 patients (50\%) achieved an ACR20 and four out of 20 an ACR50 or better response at any time point up to and including day 43 (Table 2). There was a statistically significant difference compared with placebo in terms of ACR20 improvement when all ACZ885 cohorts (one-sided $P$ $=0.043$ ) or when the $3 \mathrm{mg} / \mathrm{kg}$ and $10 \mathrm{mg} / \mathrm{kg}$ cohorts were pooled (one-sided $P=0.035$ ). Nine out of the 10 ACR20 responders satisfied criteria for response within 3 weeks after the first infusion. The time to achieve an ACR50 response was 1 week in one patient, 3 weeks in a second patient, and 4 weeks in two patients. Under placebo, three out of 15 patients exhibited an observable ACR20 response during the 6-week period of observation. One patient had an ACR20 response after 1 week, which disappeared thereafter. A second patient had an ACR2O response at weeks 1 and 3 but not on any 
Table 1

Baseline demographics of participating patients

\begin{tabular}{|c|c|c|c|c|c|}
\hline \multirow[t]{2}{*}{ Characteristic } & \multicolumn{5}{|c|}{ ACZ885 } \\
\hline & $0.3 \mathrm{mg} / \mathrm{kg}(n=6)$ & $1.0 \mathrm{mg} / \mathrm{kg}(n=6)$ & $3.0 \mathrm{mg} / \mathrm{kg}(n=6)$ & $\mathrm{mg} / \mathrm{kg}(n=20)$ & Placebo $(n=15)$ \\
\hline Age (years; mean $\pm \mathrm{SD}$ ) & $61 \pm 7$ & $53 \pm 14$ & $57 \pm 7$ & $50 \pm 11$ & $55 \pm 10$ \\
\hline hsCRP (mg/l; median [range]) & $17.8(1.6-95.3)$ & $43.8(5.8-89.3)$ & $3.0(2.0-43.4)$ & $11.1(1.5-28.4)$ & $6.4(0.2-66.2)$ \\
\hline DAS28 (mean \pm SD) & $6.5 \pm 0.8$ & $6.6 \pm 1.2$ & $6.7 \pm 1.5$ & $6.2 \pm 0.7$ & $6.7 \pm 0.6$ \\
\hline Number of tender joints (mean \pm SD) & $17 \pm 9.2$ & $15 \pm 6.2$ & $22 \pm 8.5$ & $17 \pm 7.3$ & $20 \pm 6.3$ \\
\hline Number of swollen joints (mean \pm SD) & $13 \pm 6.3$ & $12 \pm 4.3$ & $12 \pm 7.4$ & $11 \pm 4.8$ & $12 \pm 5.2$ \\
\hline \multicolumn{6}{|l|}{ Methotrexate dose ( $n / \mathrm{mg}$ median [range]) ${ }^{a}$} \\
\hline Oral & $6 / 17.5(15-25)$ & $5 / 15(10-15)$ & $4 / 15(15-15)$ & $13 / 15(10-22.5)$ & $5 / 15(10-20)$ \\
\hline Parenteral & 0 & $1 / 10(10-10)$ & $2 / 22.5(20-25)$ & $7 / 15(10-22.5)$ & $10 / 15(10-25)$ \\
\hline
\end{tabular}

aNumbers of patients receiving $15 \mathrm{mg} /$ week were $2,4,4,10$ and 6 in the $0.3,1,3,10 \mathrm{mg} / \mathrm{kg}$ and placebo cohorts, respectively. SD, standard deviation.

other occasion. The third patient had an ACR20 response after 3 weeks which continued after day 43.

Figure $3 a$ shows the mean reduction in DAS28 in the cohort treated with $10 \mathrm{mg} / \mathrm{kg}$ as compared with placebo. The $P$ values for the treatment comparisons at days 29 and 43 were 0.024 and 0.081 , respectively. Using the EULAR response criteria, a subset of five out of 20 patients treated with $10 \mathrm{mg} / \mathrm{kg}$ ACZ885 achieved a good response, and 10 out of 20 achieved a moderate response at any time point up to and including day 43 under $10 \mathrm{mg} / \mathrm{kg}$. Four out of five patients who were classified as good responders achieved the necessary DAS28 reduction within the first 3 weeks of treatment, indicating a rapid onset of action.
The fact that about $50 \%$ of all patients exhibited clinical benefit within the first 6 weeks of treatment prompted us to analyze CRP levels under therapy as a potential marker of response versus nonresponse. As shown in Figure $3 \mathrm{~b}$, there was a substantial mean reduction in and normalization of CRP within a few days after commencing treatment with $10 \mathrm{mg} / \mathrm{kg}$ ACZ885. Similarly, CRP was also reduced upon treatment in the other active treatment cohorts (data not shown). As demonstrated in Table 3 for the $10 \mathrm{mg} / \mathrm{kg}$ cohort, a reduction in CRP at day 43 was required to achieve a ACR20 or higher response; however, eight subjects had a more than $50 \%$ reduction in CRP but had no detectable clinical response based on ACR20 criteria. Thus, CRP levels declined under ACZ885 treatment in the majority of patients (14/18 patients

Table 2

\section{Clinical improvement as assessed by ACR criteria}

\begin{tabular}{|c|c|c|c|c|c|c|c|}
\hline \multirow[t]{2}{*}{ Assessor (time point) } & \multirow[t]{2}{*}{ Response } & \multicolumn{4}{|c|}{ ACZ885 } & \multirow{2}{*}{$\begin{array}{l}\text { Placebo } \\
(n=15)\end{array}$} & \multirow{2}{*}{$\begin{array}{l}P \text { value } \\
(10 \mathrm{mg} / \mathrm{kg} \text { versus } \\
\text { placebo) }\end{array}$} \\
\hline & & $\begin{array}{l}0.3 \mathrm{mg} / \mathrm{kg} \\
(n=6)\end{array}$ & $\begin{array}{l}1.0 \mathrm{mg} / \mathrm{kg} \\
(n=6)\end{array}$ & $\begin{array}{l}3.0 \mathrm{mg} / \mathrm{kg} \\
(n=6)\end{array}$ & $\begin{array}{l}10 \mathrm{mg} / \mathrm{kg} \\
(n=19 / 20 \mathrm{a})\end{array}$ & & \\
\hline \multirow{3}{*}{$\begin{array}{l}\text { Blinded observer } \\
\text { (day 43) }\end{array}$} & ACR20 & $1(17 \%)$ & $0(0 \%)$ & $4(67 \%)$ & $6(32 \%)$ & $1(7 \%)$ & 0.085 \\
\hline & ACR50 & $0(0 \%)$ & $0(0 \%)$ & $1(17 \%)$ & $3(16 \%)$ & $0(0 \%)$ & 0.162 \\
\hline & ACR70 & $0(0 \%)$ & $0(0 \%)$ & $0(0 \%)$ & $2(11 \%)$ & $0(0 \%)$ & 0.305 \\
\hline \multirow{3}{*}{$\begin{array}{l}\text { Investigator } \\
\text { (any time within } 6 \text { weeks of treatment start) }\end{array}$} & ACR20 & $3(50 \%)$ & $2(33 \%)$ & $4(67 \%)$ & $10(50 \%)$ & $3(20 \%)$ & 0.070 \\
\hline & ACR50 & $0(0 \%)$ & $0(0 \%)$ & $2(33 \%)$ & $4(20 \%)$ & $0(0 \%)$ & 0.093 \\
\hline & ACR70 & $0(0 \%)$ & $0(0 \%)$ & $0(0 \%)$ & $3(15 \%)$ & $0(0 \%)$ & 0.174 \\
\hline
\end{tabular}

Shown are the number and percentage of patients achieving 20\%, 50\%, or 70\% improvement in terms of American College of Rheumatology (ACR) criteria (ACR20, ACR50 and ACR70, respectively) at day 43 as assessed by a blinded observer and at any time point within 6 weeks of treatment start as assessed by the investigator. aNote that for one patient in the $10 \mathrm{mg} / \mathrm{kg}$ treatment group, the ACR criteria assessment by a blinded observer was not conducted at day 43. 
Figure 3

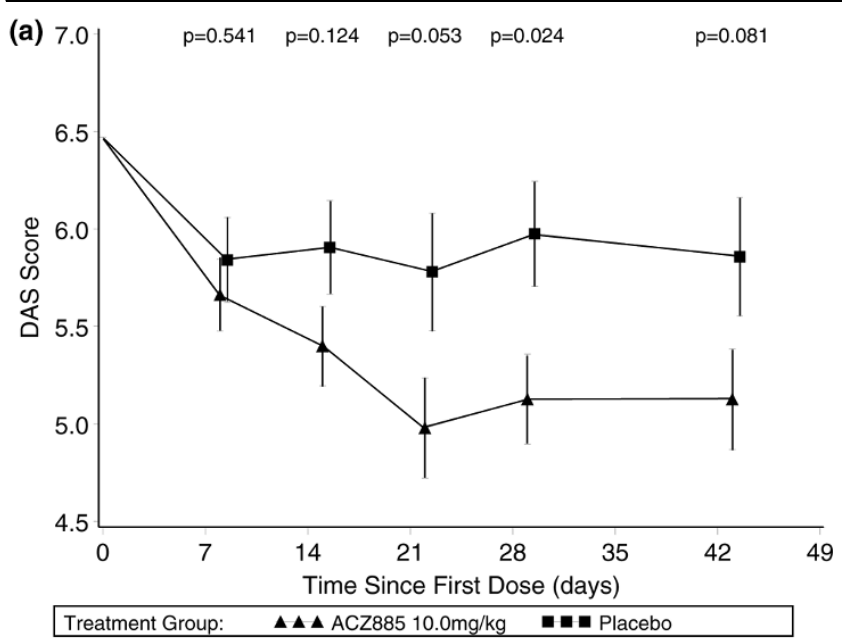

(b)

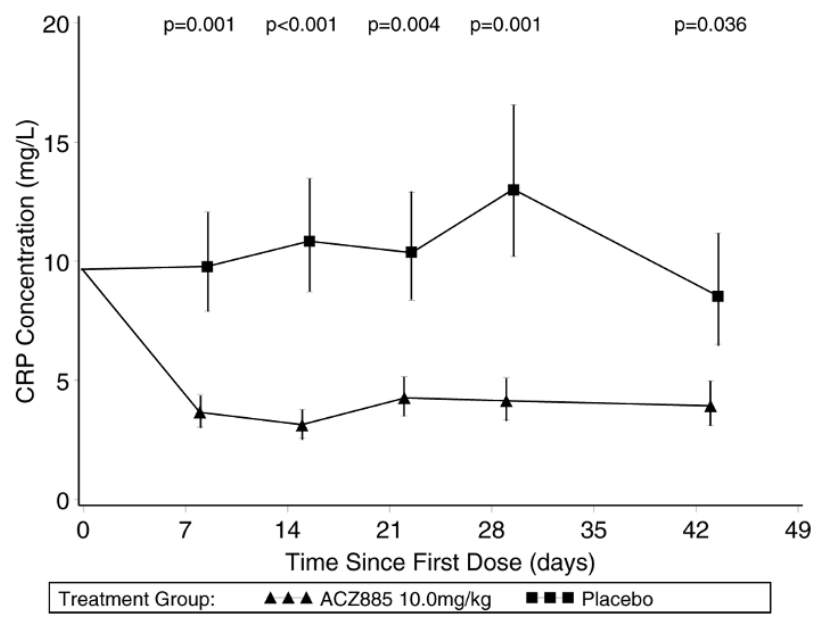

Reduction in disease activity and CRP levels following ACZ885 therapy in RA patients. (a) Mean disease activity (Disease Activity Score using 28 joint counts [DAS28]) levels over time. Baseline adjusted mean and standard error of the mean (SEM) from the repeated measures analysis are presented for patients treated with ACZ885 $10 \mathrm{mg} /$ $\mathrm{kg}(n=20)$ and placebo $(n=15)$. $P$ values for comparison of ACZ885 $10 \mathrm{mg} / \mathrm{kg}$ versus placebo at each time point are presented. (b) Geometric mean C-reactive protein (CRP) levels over time. Baseline adjusted mean and SEM from the repeated measures analysis are presented after transformation back onto the original scale for patients treated with ACZ885 $10 \mathrm{mg} / \mathrm{kg}(n=20)$ and placebo $(n=15) . P$ values for comparison of ACZ885 $10 \mathrm{mg} / \mathrm{kg}$ versus placebo at each time point are presented. Normal range of CRP was 0 to $8.4 \mathrm{mg} / \mathrm{l}$.

amenable for analysis), but only six of the CRP responders achieved an ACR20 response at day 43. Within the placebo cohort (Table 3 ), the majority of patients $(n=10)$ did not exhibit any meaningful CRP reduction $(<20 \%)$; however, CRP was reduced by more than $50 \%$ in three patients, but this was not associated with an ACR20 response.

The serum concentrations of ACZ885 were determined in each dose group. The maximal concentration rose in a dose- proportional manner and reached a mean peak exposure of $329 \mu \mathrm{g} / \mathrm{ml}$ in the $10 \mathrm{mg} / \mathrm{kg}$ group after the second infusion, which decreased to less than $10 \mu \mathrm{g} / \mathrm{ml}$ by day 113 . The elimination half-life was similar across all dose levels and averaged $21.5 \pm 4.9$ days (mean \pm standard deviation). Details of exposure and its relationship to pharmacodynamic activities of ACZ885 will be reported elsewhere.

\section{Safety and tolerability}

During the study five serious adverse events leading to hospitalization were identified. Among them, two events in the 10 $\mathrm{mg} / \mathrm{kg}$ dose group (fracture of the left trochanter major after a bicycle fall and one case of tracheobronchitis) and one in the $0.3 \mathrm{mg} / \mathrm{kg}$ group (potential recurrence of angina pectoris) were considered not to be related to the study medication. Two episodes identified in the $1 \mathrm{mg} / \mathrm{kg}$ dose group (one case of erysipelas and one case of pulmonary infection) were considered to be related to study medication. All patients with infectious events were treated with antibiotics and recovered fully within the expected time frame. None of the patients prematurely discontinued treatment because of adverse events. There were no infusion-related adverse events; in particular, no anaphylactic or anaphylactoid reactions were reported. Serum samples were tested for the presence of anti-ACZ885 antibodies at baseline, on days 43 and 71 , and at the end of the study (day 113). No formation of anti-ACZ885 antibodies was detected at any time point during the study.

The overall adverse event profile was almost the same for active and placebo treatment. Headache was reported less frequently with ACZ885 treatment $(28.9 \%$ versus $46.7 \%$ for placebo), and urinary tract infection was reported frequently often with ACZ885 (21\% versus $6.7 \%$ for placebo). Overall, intravenous administration of ACZ885 up to $10 \mathrm{mg} / \mathrm{kg}$ given twice with 14 days between dosing was found to be well tolerated without evidence of immunogenicity.

\section{Discussion}

ACZ885, a novel human monoclonal antibody directed against human IL-1 $\beta$, was found to be highly active in inhibiting IL-1 $\beta$ mediated arthritis in a preclinical animal model. The low $\mathrm{ED}_{50}$ observed in this model of aggressive inflammation is remarkable, because the injected recombinant cells constitutively secrete human IL-1 $\beta$ without any physiological feedback control. These results prompted us to study ACZ885 in a dose-escalating, proof-of-concept study in patients with RA the first of its kind in humans. The study's primary objective was to investigate safety and tolerability; therefore, it was not powered to investigate efficacy or to draw firm conclusions regarding superiority or inferiority to treatment with anakinra or TNF blockers in RA. The small sample size of 38 patients treated with various doses of ACZ885 and 15 patients on placebo does not allow any definitive conclusion about safety to be drawn. Whether an increase in infectious episodes under ACZ885 represents an early sign of the consequences of 
Table 3

Relationship between CRP reduction and ACR response following ACZ885 treatment

\begin{tabular}{lllll}
\hline \multirow{2}{*}{ Group } & CRP reduction at day 43 versus baseline & \multicolumn{2}{c}{ ACR response at day 43 } \\
\cline { 3 - 4 } & & $<20 \%$ & $20 \%$ to $<50 \%$ & $50 \%$ or more \\
\hline $10 \mathrm{mg} / \mathrm{kg} \mathrm{ACZ885}$ & $<20 \%$ & 4 & 0 & 0 \\
& 20 to $<50 \%$ & 0 & 1 & 2 \\
Placebo & $50 \%$ or more & 8 & 2 & 0 \\
& $<20 \%$ & 9 & 1 & 0 \\
& $20-<50 \%$ & 2 & 3 & 0
\end{tabular}

Relationship between C-reactive protein (CRP) reduction and American College of Rheumatology (ACR) response at day 43 for patients in the 10 $\mathrm{mg} / \mathrm{kg}$ group and patients receiving placebo. Note that two subjects are excluded from the $10 \mathrm{mg} / \mathrm{kg} \mathrm{ACZ885} \mathrm{because}$ of missing data.

blocking IL-1 - similar to observations with anakinra [21] needs confirmation, and careful monitoring in upcoming larger studies is required. Immunogenicity and infusion-associated events were not observed with two intravenous administrations.

The study provides evidence of a treatment effect by demonstrating that $50 \%$ of patients achieved an ACR20 response up to day 43 in the highest tested dose of $10 \mathrm{mg} / \mathrm{kg}$ intravenous, along with a robust reduction in serum CRP. No firm conclusion regarding any dose-response relation can be drawn, because of the small sample size $(n=6)$ of the cohorts treated with $0.3,1$, and $3 \mathrm{mg} / \mathrm{kg}$ ACZ885. The onset of action in those who responded was found to be rapid. The majority of these responders satisfied the EULAR criteria for moderate or good response or ACR20 response criteria within 3 weeks. Similar to experience with other biologics for the treatment of RA patients, there was a subset of patients who did not respond to treatment. On the other hand, some patients achieved an ACR50 or even ACR70 response within a short period of treatment. This observation reflects the common understanding that RA represents a heterogeneous disease and that, even by applying strict inclusion criteria, the studied disease in clinical trials is not homogenous. Therefore, a better understanding of the pathophysiology on an individual basis is required if we are to better predict the response to a certain treatment and hence avoid treatment failures. Consequently, there is a need to establish biomarkers that have high predictive value; recent progress has been made for TNF blockers $[22,23]$.

In the current study, CRP reduction was found to be necessary for achievment of clinical response, as expected, but it was not sufficient to explain or even predict clinical response, because CRP reduction was also observed in the absence of clinical response. Therefore, CRP reduction during treatment does not serve as a predictive biomarker for clinical responses at the individual level. Furthermore, levels of serum IL-6, TNF$\alpha$ and IL-1Ra levels (as measured by enzyme-linked immuno- sorbent assay) were within the normal range in these patients and exhibited no conclusive changes during the course of the study (data not shown). At baseline, total IL-1 $\beta$ levels in serum were at or below the detection limit of the assay (about $1 \mathrm{pg} /$ $\mathrm{ml}$ ) and showed no difference between responders and nonresponders, indicating that baseline serum levels of these cytokines are of poor predictive value to identify treatment responders.

Almost all rheumatologists prefer to administer a TNF blocker rather than anakinra as a first biologic agent to treat RA patients, concordant with a recent consensus statement, and national and international registries [3]. Treatment with recombinant IL-1Ra (anakinra) has been shown to be effective in RA [24], but its efficacy appears to be lower than that of TNF- $\alpha$ inhibitors [25] and its administration is frequently associated with injection-related adverse events. Whether anakinra's lower efficacy is due to an inferior biologic role of IL-1 as compared with TNF- $\alpha$ in the pathogenesis of RA or is simply due to the fact that anakinra cannot fully neutralize $\mathrm{LL}-1$ is currently unclear. ACZ885 can completely neutralize IL-1 $\beta$ over a long period of time; it therefore offers an opportunity to study the relative biological role of IL-1 $\beta$ in the pathogenesis of RA. Further and larger studies will determine the efficacy of ACZ885 in treating signs and symptoms in patients with RA, and they may allow comparison with the efficacies of other biologic agents.

\section{Conclusion}

ACZ885 was found to inhibit IL-1 $\beta$ mediated joint inflammation in preclinical models. It was well tolerated in this first proof-of-concept study in RA patients and was associated with a significant treatment effect in about $50 \%$ of patients. Further studies are warranted to confirm these initial results, to establish a safety profile, to identify those patients who will profit most from blocking $\mathrm{IL}-1 \beta$, and to better understand the biological role played by $\mathrm{IL}-1 \beta$ in the pathogenesis of RA. 


\section{Competing interests}

This study was sponsored by Novartis Pharma AG, Exploratory Development, Basel, Switzerland. CR, AMW, TW, GJMB and TJ hold Novartis stock options and shares. WvdB has received Novartis funds to study cytokines in arthritis models. $H G$ is author on patents related to ACZ885. GB and RA have acted as consultants for Novartis. The authors declare that they have no further competing interests.

\section{Authors' contributions}

RA, JS, SW, GB and PvR conducted the clinical study as investigators and contributed to the writing of the manuscript. $\mathrm{LJ}, \mathrm{WvdB}$ and HG performed the preclinical studies and contributed to the writing of the manuscript. TW and CR planned and initiated the clinical study and reviewed the data, YB wrote the trial protocol, MDL was the lead monitor, GJMB the lead pharmacokineticist and AMW the lead statistician. TJ reviewed and interpreted the data, wrote the manuscript and is responsible for the exploratory clinical development programme of ACZ885.

\section{Acknowledgements}

The contributions of C Gabay (Geneva), P Villiger (Bern), D Uebelhart (Zuerich), H Dammann (Hamburg), S Schewe (Muenchen), Wseidel (Leipzig), A Perniok (Cologne) and FC Breedveld (Leiden) as further investigators in the clinical trial are highly appreciated.

\section{References}

1. Smolen JS, Steiner G: Therapeutic strategies for rheumatoid arthritis. Nat Rev Drug Discov 2003, 2:473-488.

2. Dinarello CA: The IL-1 family and inflammatory diseases. Clin Exp Rheumatol 2002, 20:S1-S13.

3. Furst DE, Breedveld FC, Kalden JR, Smolen JS, Burmester GR, Emery P, Keystone EC, Schiff MH, Van Riel PL, Weinblatt ME, Weisman MH: Updated consensus statement on biological agents for the treatment of rheumatic diseases, 2006. Ann Rheum Dis 2006, 65(suppl 3):iii2-iii15.

4. Burger D, Dayer JM, Palmer G, Gabay C: Is IL-1 a good therapeutic target in the treatment of arthritis? Best Pract Res Clin Rheumatol 2006, 20:879-896.

5. Dinarello CA: Therapeutic strategies to reduce IL-1 activity in treating local and systemic inflammation. Curr Opin Pharmacol 2004, 4:378-385.

6. Joosten LA, Helsen MM, Loo FA van de, Berg WB van den: Anticytokine treatment of established type II collagen-induced arthritis in DBA/1 mice. A comparative study using anti-TNF alpha, anti-IL-1 alpha/beta, and IL-1Ra. Arthritis Rheum 1996, 39:797-809.

7. Berg WB van den, Joosten LA, Kollias G, Loo FA van de: Role of tumour necrosis factor alpha in experimental arthritis: separate activity of interleukin 1 beta in chronicity and cartilage destruction. Ann Rheum Dis 1999, 58(suppl 1):140-148.

8. Loo FA van de, Arntz OJ, Otterness IG, Berg WB van den: Protection against cartilage proteoglycan synthesis inhibition by antiinterleukin 1 antibodies in experimental arthritis. J Rheumatol 1992, 19:348-356.

9. Tak PP, Bresnihan B: The pathogenesis and prevention of joint damage in rheumatoid arthritis: advances from synovial biopsy and tissue analysis. Arthritis Rheum 2000, 43:2619-2633.

10. Olszewski WL, Pazdur J, Kubasiewicz E, Zaleska M, Cooke CJ, Miller NE: Lymph draining from foot joints in rheumatoid arthritis provides insight into local cytokine and chemokine production and transport to lymph nodes. Arthritis Rheum 2001, 44:541-549.
11. Dayer JM: The pivotal role of interleukin-1 in the clinical manifestations of rheumatoid arthritis. Rheumatology (Oxford) 2003, 42(suppl 2):ii3-ii10.

12. Lettesjo $H$, Nordstrom $E$, Strom $H$, Nilsson $B$, Glinghammar $B$, Dahlstedt L, Moller E: Synovial fluid cytokines in patients with rheumatoid arthritis or other arthritic lesions. Scand J Immunol 1998, 48:286-292.

13. Holt I, Cooper RG, Denton J, Meager A, Hopkins SJ: Cytokine inter-relationships and their association with disease activity in arthritis. Br J Rheumatol 1992, 31:725-733.

14. Kahle P, Saal JG, Schaudt K, Zacher J, Fritz P, Pawelec G: Determination of cytokines in synovial fluids: correlation with diagnosis and histomorphological characteristics of synovial tissue. Ann Rheum Dis 1992, 51:731-734.

15. Cunnane G, Madigan A, Murphy E, Fitzgerald O, Bresnihan B: The effects of treatment with interleukin-1 receptor antagonist on the inflamed synovial membrane in rheumatoid arthritis. Rheumatology (Oxford) 2001, 40:62-69.

16. Bresnihan $B$, Cobby $M$ : Clinical and radiological effects of anakinra in patients with rheumatoid arthritis. Rheumatology (Oxford) 2003, 42(suppl 2):ii22-ii28.

17. Ghivizzani SC, Kang R, Georgescu HI, Lechman ER, Jaffurs $D$, Engle JM, Watkins SC, Tindal MH, Suchanek MK, McKenzie LR, Evans $\mathrm{CH}$, Robbins PD: Constitutive intra-articular expression of human IL-1 beta following gene transfer to rabbit synovium produces all major pathologies of human rheumatoid arthritis. $J$ Immunol 1997, 159:3604-3612.

18. Joosten LA, Loo FA van de, Lubberts E, Helsen MM, Netea MG, Der Meer JW, Dinarello CA, Berg WB van den: An IFN-gammaindependent proinflammatory role of IL-18 in murine streptococcal cell wall arthritis. J Immuno/ 2000, 165:6553-6558.

19. Finkelman FD, Madden KB, Morris SC, Holmes JM, Boiani N Katona IM, Maliszewski CR: Anti-cytokine antibodies as carrier proteins. Prolongation of in vivo effects of exogenous cytokines by injection of cytokine-anti-cytokine antibody complexes. J Immunol 1993, 151:1235-1244.

20. Alten RHE, Pohl CCP, Batard YB, Wright AAW, Gram HHG, Bobadilla MMB, Bruins GGB, Woodworth TTW: ACR 20/50/70 responses in methotrexate-resistent rheumatoid arthritis (RA) patients in a double-blind, placebo-controlled phase I/II evaluation of the pharmacokinetics/pharmacodynamics (PK/PD), safety, and preliminary efficacy of a fully human anti interleukin 1 antibody. Ann Rheum Dis 2006, 65(suppl II):60.

21. Salliot C, Dougados M, Gossec L: Risk of serious infections during rituximab, abatacept and anakinra therapies for rheumatoid arthritis: meta-analyses of randomized placebocontrolled trials. Ann Rheum Dis 2008 in press.

22. Lequerré $T$, Gauthier-Jauneau $A C$, Bansard $C$, Derambure $C$, Hiron M, Vittecoq O, Daveau M, Mejjad O, Daragon A, Tron F, Le Loët X, Salier JP: Gene profiling in white blood cells predicts infliximab responsiveness in rheumatoid arthritis. Arthritis Res Ther 2006, 8:R105.

23. Lequerre $T$, Jouen $F$, Brazier M, Clayssens $S$, Klemmer N, Menard JF, Mejiad O, Daragon A, Tron F, Le Loët X, Vittecoq O: Autoantibodies, metalloproteinases and bone markers in rheumatoid arthritis patients are unable to predict their responses to infliximab. Rheumatology (Oxford) 2007, 46:446-453.

24. Furst DE: Anakinra: review of recombinant human interleukinI receptor antagonist in the treatment of rheumatoid arthritis. Clin Ther 2004, 26:1960-1975.

25. Gartlehner G, Hansen RA, Jonas BL, Thieda P, Lohr KN: The comparative efficacy and safety of biologics for the treatment of rheumatoid arthritis: a systematic review and metaanalysis. $J$ Rheumatol 2006, 33:2398-2408. 